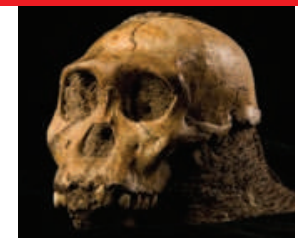

'HUMAN ANCESTOR' SPARKS FURORE

Does fossil represent a new hominin species? www.nature.com/news

\title{
Q\&A: What it will take to feed the world
}

\author{
Marion Guillou is the chief executive of France's National Institute for Agricultural Research, Europe's \\ largest agricultural-research agency. She talks to Declan Butler about how researchers are trying to meet \\ the challenge of feeding a world population that is estimated to grow to 9 billion people by 2050.
}

\begin{abstract}
Agricultural researchers held the first ever Global Conference on Agricultural Research for Development last week in Montpellier. What came out of that?

The conference showed that agricultural researchers are mobilized and recognize themselves as a global community. At the same time, there is strong tension between the CGIAR [Consultative Group on International Agricultural Research] international research centres and the global agricultural research community. The centres tend to be too closed to those outside, and there is pressure to open them up to national and other agricultural research bodies.

Developing countries at the conference also sent a strong message about the return in strength of family farms; that making these more productive is key to both alleviating poverty and meeting local and global food demand. It's a new political message: count on and help small farms. The international focus has long been on large-scale industrial farming, so this changes quite a few things. The themes of research for smallholdings are very different from those of large-scale farming, involving, for example, concepts such as crop rotation, complements of animals and plants, and the use of animal waste as fertilizer, so the research questions are not the same.
\end{abstract}

\section{What are the most promising routes to feeding 9 billion people?}

The first priority is to fight loss and waste. We lose as much as 30 to $35 \%$ of the world's food output. That gives us a large margin of manoeuvre to increase the food available. We are doing research with food processors and distributors to explore solutions. We certainly won't be able solve the problem, but we can improve it.

Diet will also be a major determinant in our capacity to nourish the world [animal products require considerably more energy and land than plants]. We need to ensure food availability of 3,000 kilocalories a day per person, of which only 500 kilocalories is from animal products - we are not trying to transform everyone into vegetarians. This provides a healthy and satisfying diet, but is far from a typical Western diet. If we continue

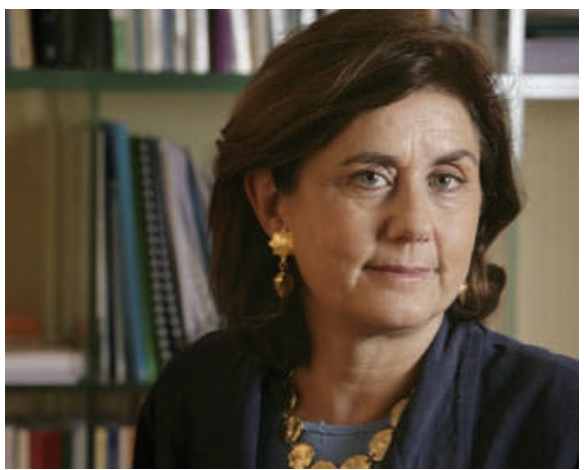

the current dietary regime typical of OECD [Organisation for Economic Co-operation and Development] countries, and if many other countries follow us on this trajectory, we will not have the same results in terms of food availability as we would with a more moderate diet worldwide.

\section{What's the role of food prices?}

One really big research area is studying the volatility of prices. It is the main problem. Remember the food riots in several countries in 2008? We are still trying to understand what happened, but much of it was because of financial speculation. We already have enough food to feed everyone on the planet at 3,000 kilocalories per day, but it is a question of price. We need research to find out which economic tools are available to stabilize prices at the international level, and to ensure, for example, adequate available reserves of cereal. We need to propose economic solutions, and regulation of markets of agricultural foodstuffs to avoid the yo-yo whereby prices can go so high that people do not have access to food. We also have to guarantee minimum prices if farming is to remain viable.

\section{Much media coverage on developing- world agriculture has focused on genetically modified organisms (GMOs). Are these the silver bullets they are often made out to be?}

It's clear that genetic progress in the past in France and other rich countries accounted for much of the increase in production, so genetics is far from passé; it's still the number-one technique for increasing yields, for example. For Africa to improve its yields, we clearly need new genetically selected varieties, engineered by either genetic modification or classic breeding techniques. For me, GMOs are not a magic bullet, but we should not refuse them a priori. It's critical to look at GMOs on a case-by-case basis. The first generation of genetically modified organisms on the market is not the one that will solve Africa's problems, although one crop, a Chinese GMO cotton that is resistant to bollworm, has proved extremely useful to the population, because it avoids the spraying of dangerous pesticides - the risk-benefit equation is clearly in favour of its use.

We are now at a stage where we have years of extensive research results on the ecological, economic and health aspects of many GMOs. There are GMOs for which the assessment is undisputedly positive, but there are others - in particular some crops engineered to be resistant to this or that herbicide - for which this is not so. For example, some GMOs result in increased use of herbicides, which can lead to concentration of these chemicals in the environment and negative effects. The results are mixed - that's why it is important not to speak of GMOs in general, but case-bycase. Pest resistance is a really promising and important application for genetic selection because there are a lot of health problems in developing countries that have been linked to the spraying of pesticides.

\section{Public funding of agricultural research} in rich countries has declined, and is increasingly shifting to the private sector, which has less interest in the needs of poorer countries. What's the overall funding outlook?

We need to continue to innovate and reinvest, in particular to increase yields. This isn't happening in rich countries, but worldwide budgets are on the increase - largely in emerging economies such as China, India and Brazil. China is heavily involved in training and technology transfer to Africa, and in Europe we should be trying to offer Africans an alternative; we have the scientific capacity. It would be a pity if we were to leave all collaborations in the hands of the Chinese. This is a translated and edited version of an interview conducted in French. 